\title{
Rating Assessment System for Development Effectiveness of Social Entrepreneurship in Agrarian Sector
}

\author{
Guzal Rinatovna Tsareva \\ Vladimir Ivanovich Shulepov
}

Volga State University of Technology

Email: sci.publ@gmail.com

Doi:10.5901/mjss.2015.v6n1s1p554

\begin{abstract}
This article represents a review of some formation and functioning peculiarities of social entrepreneurship and discovers the essential peculiarities of that category in the agrarian sector of the modern Russian economy. To ensure effective control of the social business development at various stages of the life cycle, we suggest a rating assessment system for the development effectiveness of social entrepreneurship in the agrarian sector. We used the economical, social and strategic effectiveness components as the basic criteria for building the assessment system, with the weight coefficients taken into consideration. Basing on the analysis of the information provided by the Ministry of Agriculture of Russia and the Ministry of Economic Development of Russia, we suggested a polynomial mathematical model to forecast the profitability of investments in a project for development of social entrepreneurship in the agrarian sector of the modern Russian economy, depending on the development coefficient value of the social entrepreneurial structure.
\end{abstract}

Keywords: social entrepreneurship in agrarian sector, rating assessment system, polynomial mathematical model.

\section{Introduction}

The precondition for social entrepreneurship is the ineffective distribution of the resources ("market downfalls") which require governmental interference in the economic processes in order to reallocate the production factors. At the same time, the high transaction costs of the governmental bodies' operations, which consist of the costs for information search and the ones caused by the opportunistic behavior of the bureaucratic apparatus officials in the conditions of the high turbulence of the external environment, as well as the polarization of the economic space, make it necessary to localize the process of public goods reproduction (Evert-janQuak, 2014).

On the one hand, the improving welfare of the society causes the growing demand for public goods, and on the other hand, it makes for the growing value of the highest needs (according to A. Maslow). The postindustrial economy characterized by the dominating role of the human capital in ensuring the growth of the total revenue stimulates investments in its accumulation, which in turn becomes possible only if differentiated public goods are available. Social entrepreneurship formation is promoted by the economic space informatization and networkization resulting in reduction of the transaction costs of the information search with respect to the instruments of entrepreneurial activities and the content of managerial decisions (Nikolaev N. , 2014).

\section{Research Methodology}

The following methods were used in the study: analysis of the conceptual and terminological system, analog method, prognostication, and a group of statistical methods, such as summary and grouping method, correlation and regression analysis, sampling observation, and analysis of the rows of dynamics (Ivashkin S.V. , 2011).

When analyzing the efficiency for the control purposes, it is required to consider the main principles that the financing of the state expenses is based on (including those when allotting the funds intended implementation of the target programs). In this case, the methods used to assess the agrarian sector can be applied to control the efficiency of the use of the state resources.

The content of the local public goods provided by social entrepreneurs reflects the content of the needs of the local community as well, thus ensuring their full satisfaction. The participation of social enterprises in production of the public goods is conditioned by their mixed character, which allows the possibility to apply the governmental control and market 
self-control methods. Governmental control is mainly implemented through establishing institutions that stimulate enterprises to select social orientation for their activities: taxation, budgeting and lending institutions that provide corresponding preferences for enterprises and institutions that provide authorization to establish noncommercial organizations (funds) which provide loans and information and consultation services at the stages of formation and development of social enterprises, as well as institutions that stimulate development of the market for educational services, which ensures sharing of the social entrepreneurship knowledge and skills. The social innovations implemented by social enterprises are mainly of developing character, which does not imply any considerable investments (Lakshmi Karan, Nina Smith, Steven Rockhold, Dara O'Rourke , 2014).

\section{Findings and Discussion}

Formation of a certain type of market structures, including agrarian sector, may, on the whole, be regarded as a response to excessive transaction costs. At this point, integration processes in Russia are characterized by aggregation and consolidation of enterprises. This implicitly proves the desire for diversification and economic control of enterprise risks associated with imperfect institutional environment and excessive transaction costs. It should be noted that control over efficiency of costs or any other category may be an extremely complicated and expensive procedure. An example would be the control which the government exercises over taxpayers since it has to maintain the costly tax-collection apparatus.

One of the most interesting ways to optimize the efficiency control of transaction costs consists in eliminating excessive control procedures and reducing the amount of data being collected. The main principle that should be adhered to is reduction of excessive information, i.e. 'do not collect more information than you can process'.

Sometimes data collection services do not manage to analyze information, all their time is spent on collecting it. It would be reasonable to focus on weakest aspects, i.e. areas where problems arise more often. This would allow to solve the core of the problem more efficiently while saving transaction costs related to data collection and processing.

Integration trends in the Russian economy are mainly associated with transition processes and enterprises' adaptation to the imperfect market conditions. The natural reaction of a rational economic agent to excessive transaction costs would be trying to independently reduce them. But as a result, the reproduction system may fall into an institutional trap. Since it is impossible to rely on natural tendencies of transaction costs to decrease, the need arises for the government active interference in the process of their 'natural' reduction.

As a subject of government control, dual nature of transaction costs, especially transformation processes with a high share of informal sector, as well as significant difference in conditions of functioning of various types of markets require a differentiated approach to transaction costs reduction in the national economy.

Comprehensive mechanism for efficiency control of transaction costs which is used in economy to reduce them involves development of ideology, specification and protection of property rights, standardization of measurements, accounting and reporting, maintenance of monetary system, improvement of law enforcement effectiveness and efficiency, as well as implementation of measures aimed at eliminating unnecessary administrative burdens and infrastructure markets of various transactions.

The basic requirements of institutional changes include recognition of the critical role of the government control of economic development; government's commitment to economic development; accounting of institutional transformation costs; review of efficiency of the current control.

The dynamics of the transaction costs contributes to the development of social entrepreneurship. In particular, if the transaction costs of production and consumption of the national public goods are higher than those of production of the local public goods, it results in choosing the distributed model of their reproduction (.Larionova N.I., Yalyalieva T.V., Napolskikh D.L., 2014)

At the same time, the condition of the internal environment of enterprises is regulated by formal and informal institutions that ensure routinization of the contractual relations and preservation of the traditions as a stable development factor of the permanent character of the social projects being implemented. Among the informal institutions of that kind, an important role is played by the religious world outlook as an essential element of the mechanism for entrepreneurial activity self-regulation, replication of the social initiatives, disintegration of the property rights, and distribution of the profit between economic and social needs.

Hence, the contradiction between the orientation at obtaining the economic and social results can be settled providing that an effective institutional environment is established, which ensures minimization of the transaction costs, such as the costs of the pre-contractual stage (registration, information search on the content and structure of the public goods offer, the subject structure of the counteragents, etc.), the costs of the contractual stage (opportunistic behavior of the counteragents and governmental bodies, etc.), and the costs of the post-contractual stage (contract enforcement 
etc.).

The content of the institutions designed by the state differs from that of the institutions designed by the business community, depending on the scale of the activities and on the type of the economic activities performed by social enterprises.

The distinguishing peculiarities of social entrepreneurship, along with the characteristic features typical of the activities performed by agrarian sector enterprises, determine the specific development character of the business of that type at different stages of the business structure life cycle. The establishment stage of a social business structure in the agrarian sector is longer than the same stage of the life cycle of a traditional enterprise, which results from the instability of the legal domain that the social enterprises operate in (Catherine Clifford, 2013), (Bill Drayton, 2012).

As a rule, the activities performed by social business structures is not regulated by the current normative legal acts, which govern either the activities of noncommercial organizations or those of the business structures oriented at profit extraction. Since social entrepreneurship is a combination of both commercial and noncommercial organizations, certain aspects of such activities appear beyond the applicable legal control domain, and elimination of the contradictions resulting from it makes the establishment stage considerably longer. In the agrarian sector, the situation described above becomes even more complicated because of the necessity to finish the establishment stage within a certain period of time, and so the first stage of the life cycle of a social business is normally longer than in other businesses.

Due to the relatively low profitability generated by social enterprises (as a rule, the profitability of agricultural companies is lower than in other industries), the development risks of a business structure during the formation stage are considerably higher than for any similar companies of the traditional businesses, and even in case this stage is successfully completed, it still takes longer than it does with commercial enterprises. Besides, as shown by the practical analysis of Russian companies, the probability of organizations closing at this stage is $30 \%$ to $40 \%$ higher in the agrarian sector if compared with social enterprises operating in service industries, (Tania Ellis, 2010)

The maturity stage of a social business structure in the agrarian sector is characterized by the stability of the business model of such an enterprise and by a stable growth in the consumption of its products, which results from the necessity to use the network effects (appearing due to the strong cohesion of the target consumer community of social enterprises) and the scale effect, which makes for a gradual growth of the social effectiveness of the social business, preserving at least the economic effectiveness of the entrepreneurial activities which was reached in the beginning of the maturity stage. Unlike the establishment and formation stages, the decline stage for a social business in the agrarian sector passes faster if compared with the similar development stages of a commercial organization, which is caused by a lower business model stability of social enterprises (Shakirova G.R. , 2014).

Hence, controlling the development of social enterprises implies the following measures: at the establishment stage, the task of the state as the controlling body is building an institutional environment of the most-favored treatment for the development of social entrepreneurship; at the formation stage, the priority in controlling the activities of this type of enterprises is consulting services aimed at establishing and maintaining a stable business model; at the maturity stage, ensuring a stable functioning of a social business is only possible if the stability of the institutional environment is preserved; and at the decline stage, the measure required to prevent such enterprises from getting insolvent may be implementation of special readjustment procedures, which will allow reducing the obligations when the social business comes into a crisis.

An effective control of the development of a social business at the life cycle stages of such a structure implies the necessity to form a multiple-aspect system to assess the activities of a business structure of that kind.

Due to the necessity to apply the assessment criteria to the economic, social and strategic effectiveness and development efficiency of social entrepreneurship, the priority format of such an application is the rating method (see the table below). The specific share of importance of each of the parameters represented in the table in the individual and group indicators was determined on the basis of an expert assessment, with the processing results of expert opinions taken into account. 
Table 1. Rating Assessment System for Development Effectiveness of Social Entrepreneurship in Agrarian Sector

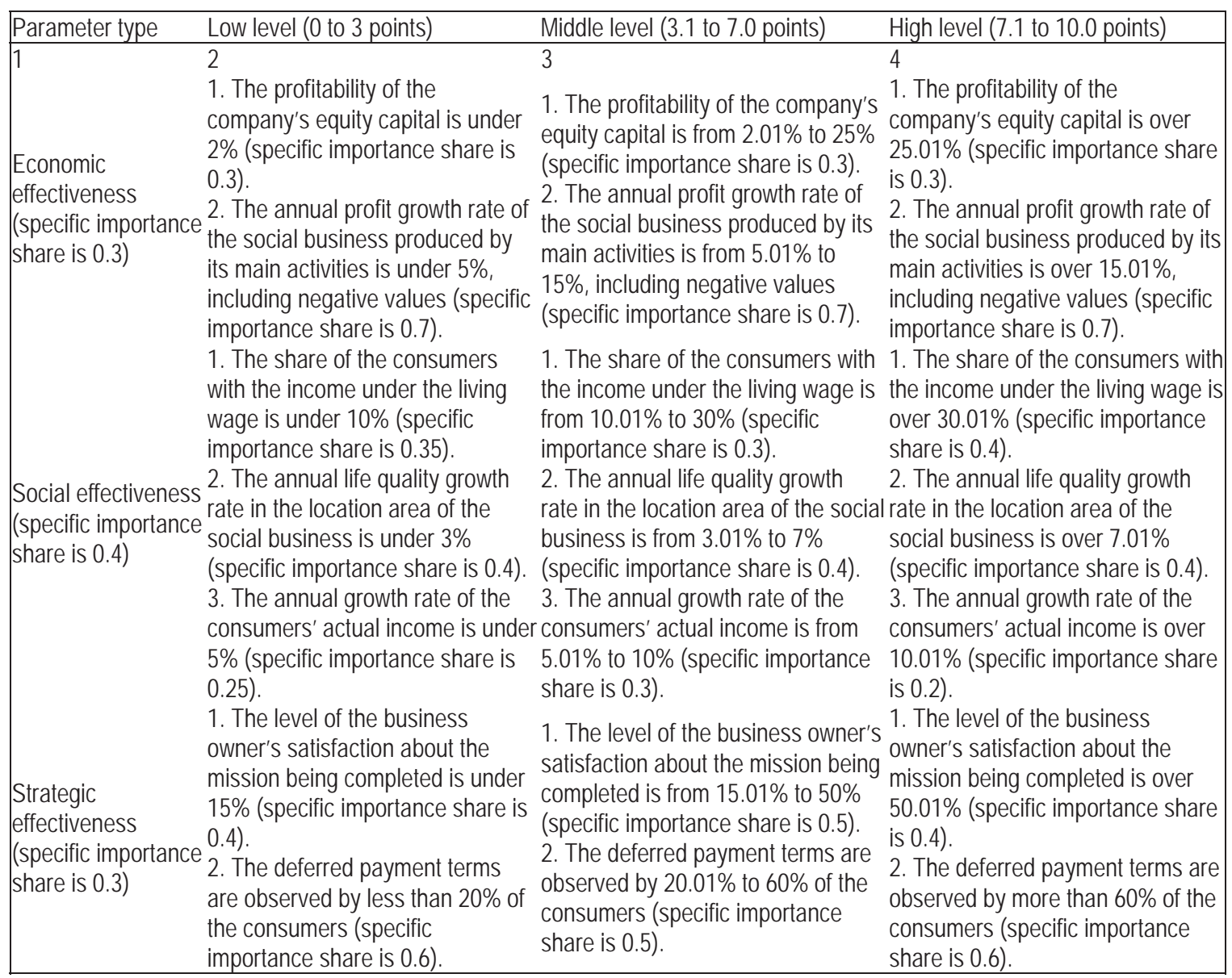

Every individual parameter represented in the table is assessed according to a ten-point system where zero corresponds to the minimal value of the parameter and ten is its maximum value. Individual criteria of the same type are contracted to a group indicator as a weight average number of points determined on the basis of the specific share of the individual criteria. The resulting integral value (coefficient) of the development level of a social business structure allows us to rank their effectiveness in the context of the multiple-factor assessment of the activities performed by a social enterprise in the agrarian sector.

\section{Concluding Remarks}

The practical analysis of the development of the Russian business structures of the agrarian sector, using the suggested rating methods, allowed us to determine that today the development levels of individual businesses of that type lie between the values of 0.2 (low development level of the social business structure) and 7.3 (high development of the social business structure). Besides, we also found a strong direct dependence between the indicated level and the profitability of the investments in the social business projects of the agrarian sector, which was calculated on the basis of the data obtained from the study of 25 Russian social business companies operating in the agrarian sector and located in various regions (mainly in Volga Federal District) (The official internet-portal of the Ministry of Agriculture of the Russian Federation, Official Internet server of the Ministry of Economic Development of the Russian Federation, 2014). 


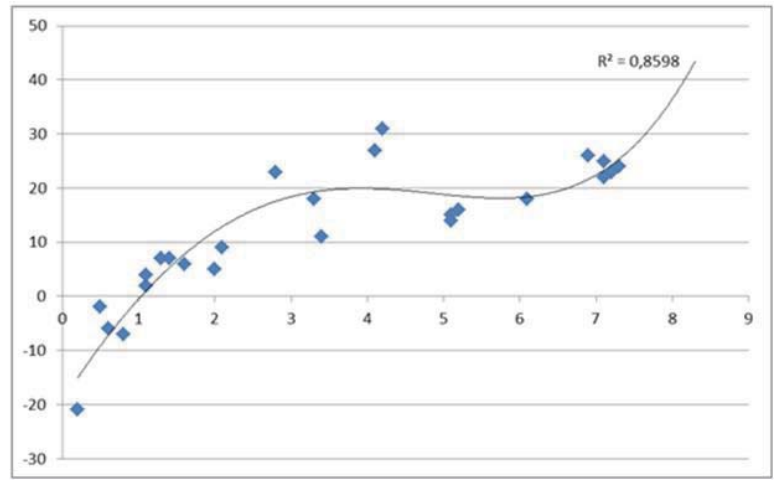

Figure 1. Dependence between the profitability of the investments in a social business structure of the agrarian sector and the development level (coefficient) of the social business structure

Basing on the data obtained there, we have built a mathematical model that allows us to determine the potential profitability level of the investments, depending on the development level of the social business structure, which is determined on the basis of the approach suggested in the research:

$\mathrm{ROI}_{\text {est }}=0,041 \mathrm{SE}_{\mathrm{dev}}^{4}-0,2049 \mathrm{SE}_{\mathrm{dev}}^{3}-2,8414 \mathrm{SE}_{\mathrm{dev}}^{2}+21,836 \mathrm{SE}_{\mathrm{dev}}-19,319$

where $\mathrm{ROI}_{\mathrm{est}}$ is the supposed profitability level of the investments in the social business structure of the agrarian sector, \%;

$\mathrm{SE}_{\mathrm{dev}}$ is the development level (coefficient) of the social business structure, points (0 to 10).

The resulting dependence is shown on the picture above, where the abscissa axis represents the development level of the social business structure, and the ordinate axis shows is the profitability level of the investments.

Extrapolation of the graph up to values of the coefficient above 8 points has shown that the profitability level of the investments may exceed 30\% (the quality of the model is quite high, which is proven by the determination coefficient of $\mathrm{R} 2=0,8598$ ( $\mathrm{p}<0,05)$, as shown on the picture).

Hence, the suggested theoretical and methodological approach to the content of social entrepreneurship and methods for controlling it will ensure growth of entrepreneurial activities and implementation of the creative potential of the enterprises, as well as socialization of the economic relations and improvement of the quality of life for the people.

Thanks. This work has been accomplished in the context of the governmental task for higher education schools and scientific organizations within the field of the scientific activities related to Project No. 2296, Institutions for Development of the Local Markets and Formation of an Innovation Cluster.

\section{References}

Bill Drayton (2012).Five Predictions For The Future Of Social Entrepreneurship. Date Views 05.09.2014 www.forbes.com/sites/ashoka/ 2012/11/19/five-predictions-for-the-future-of-social-entrepreneurship/.

Catherine Clifford (2013). For Social Entrepreneurs, What Comes First: Business or Mission?. Date Views 5.09.2014 www.entrepreneur. com/article/229648.

Evert-janQuak (2013).Social enterprises: catalysts of economic transition?. Date Views 05.09 .2014 www.thebrokeronline.eu/Articles/ Social-enterprises-catalysts-of-economic-transition.

Ivashkin, S.V. (2011).Methods of scientific and technological forecasting development organization. Date Views 05.09.2014 www. moluch. ru/ archive/28/3243/

Lakshmi Karan, Nina Smith, Steven Rockhold, Dara O'Rourke (2014).Leveraging Social Innovation. Date Views 05.09.2014 csi.gsb.stanford.edu/leveraging-social-innovation

Larionova, N.I., Yalyalieva T.V. and Napolskikh D.L., 2014. Ensuring efficiency control of institutional environment of the cluster. Am. J. Applied Sci., 11: 1594-1597. DOI : 10.3844/ajassp.2014.1594.1597 http://thescipub.com/abstract/10.3844/ajassp.2014.1594. 1597

Nikolaev , N. (2014).Social entrepreneurship has become a new ideology of business activity. Date Views 05.09.2014 www.rg.ru/2014/ 08/19/biznes.html.

Official Internet server of the Ministry of Economic Development of the Russian Federation. Date Views 05.09.2014 www.economy. gov.ru.

Shakirova, G.R. (2014). Features of social entrepreneurship in the agricultural sector. Vectors of modern science: proceedings of the international scientific-practical conference (Ufa, January 20-21, 2014), Ufa: IC ITSIPT (issue Part III.), pp: 141-143. 
Shakirova, G.R., 2014. Features of social entrepreneurship in the agricultural sector. Vectors of modern science: proceedings of the international scientific-practical conference (Ufa, January 20-21, 2014), Ufa: IC ITSIPT (issue Part III.), pp: 141-143.

Tania Ellis(2010). The New Pioneers by Tania Ellis. Date Views 05.09.2014 issuu.com/wiley_publishing/docs/new_pioneers_chap_1

The official internet-portal of the Ministry of Agriculture of the Russian Federation. Date Views 05.09.2014 www.mcx.ru. 